\title{
Valores Organizacionais e Atitudes Frente à Mudan- ça: o Caso da Polícia Militar do Distrito Federal
}

Organizational Values and Attitudes Facing change: the Case of Police

Valores Organizacionales y Actitudes frente a la Mudanza: el Caso de la Policía

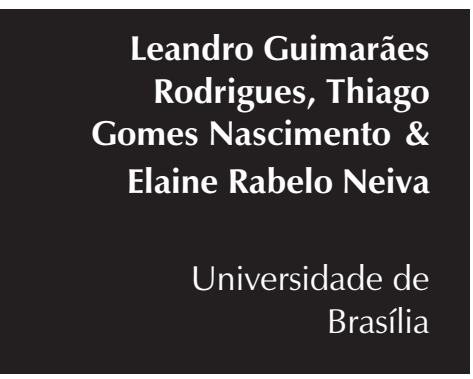

http://dx.doi.org/10.1590 / 1982 - 3703000502013

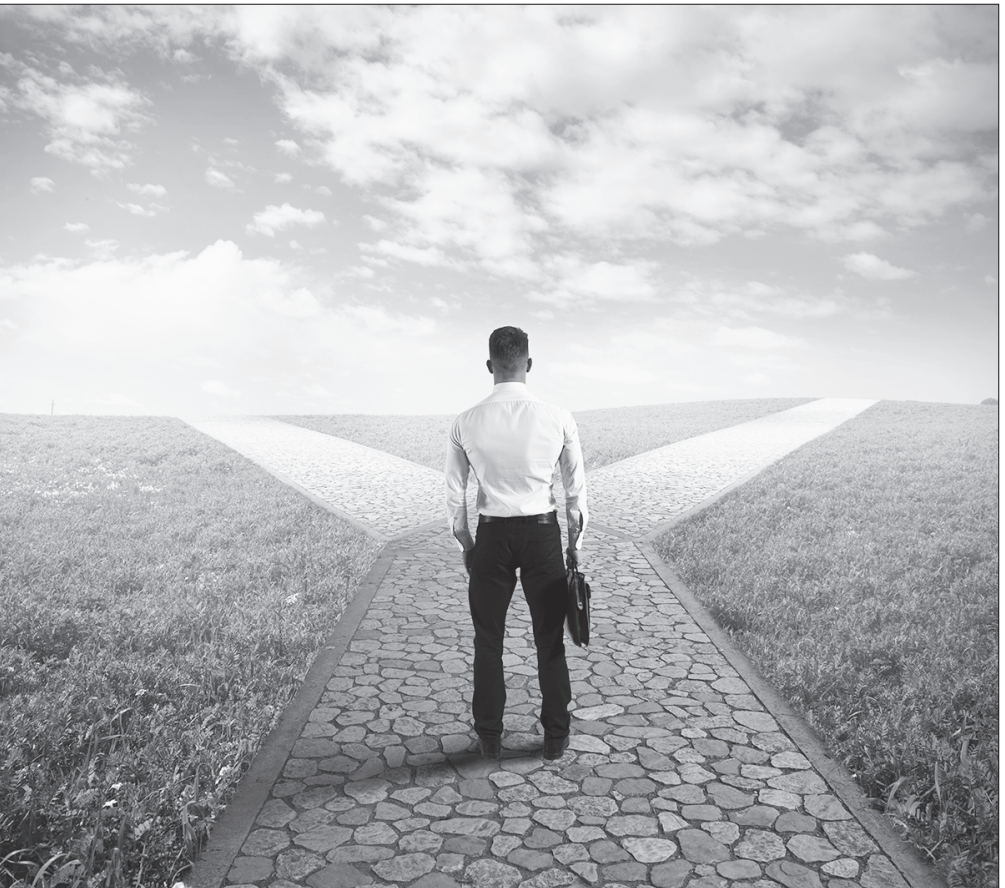


Resumo: O presente estudo objetivou levantar os valores organizacionais e as atitudes dos membros da organização frente à mudança. Foram utilizados dois instrumentos para levantamento dos valores organizacionais e das atitudes frente à mudança. Esses questionários foram administrados de forma eletrônica e estiveram disponíveis para acesso durante trinta dias. As análises estatísticas realizadas foram regressões logísticas, devido à não normalidade das variáveis em estudo, o que inviabilizou testes paramétricos e regressões lineares. Segundo os dados encontrados, valores de conservação e hierarquia são os mais presentes na organização e as atitudes dos indivíduos são de temor. Para as atitudes frente à mudança, não foi verificada diferença entre os sexos dos membros da organização. Os dados ainda revelaram que valores de hierarquia e conservação são mais percebidos pelas praças do que pelos oficiais. As praças também percebem mais todas as atitudes em comparação aos oficiais, demonstrando atitudes ambíguas em relação à mudança. O valor domínio, característico de organizações que buscam a supremacia em suas áreas de atuação, apresentou valor baixo, explicado pelo fato de a organização ter exclusividade de atribuições garantida pela Constituição Federal de 1988. A hipótese de que hierarquia e conservação implicam em atitude negativa em relação à mudança não foi confirmada.

Palavras-chave: Atitudes. Mudança. Valores. Clima organizacional. Polícia Militar - Brasília.

\begin{abstract}
The present study aimed to raise the organizational values and attitudes of organization members facing change. Two instruments were used to survey organizational values and attitudes towards change. These questionnaires were administered electronically and were available to access for thirty days. The statistical analyses performed were logistic regressions, due to non-normality of variables under study, which impeded parametric tests and linear regressions. According to the data found, conservation and hierarchy values are the most present in the organization and the attitudes of individuals are of fear. For attitudes towards change, no difference has been found between the genders of the organization members. The data also revealed that hierarchy and conservation values are more perceived by enlisted rank than by officers. Those from enlisted ranks also realize more every attitudes as compared to officers, demonstrating ambiguous attitudes toward change. The domain value, characteristic of organizations seeking the upper hand in their areas of practice, presented low value, explained by the fact the organization has exclusive powers guaranteed by the Federal Constitution of 1988. The hypothesis that hierarchy and conservation imply negative attitude towards change has not been confirmed.
\end{abstract}

Keywords: Attitudes. Change. Values. Organizational climate. Military Police - Brasília.

Resumen: El presente estudio objetivó analizar los valores organizacionales y las actitudes de los miembros de una organización frente a las mudanzas. Fueron utilizados dos instrumentos para análisis de los valores organizacionales y de las actitudes frente a la mudanza. Esos cuestionarios fueron administrados de forma electrónica y estuvieron disponibles para acceso durante treinta días. Los análisis estadísticos realizados fueron regresiones logísticas, debido a la no normalidad de las variables en estudio, lo que inviabilizó tests paramétricos y regresiones lineales. Según los datos encontrados, valores de conservación y jerarquía son los más presentes en la organización y las actitudes de los individuos son de temor. Para las actitudes frente a la mudanza, no fue verificada diferencia entre los sexos de los miembros de la organización. Los datos asimismo revelaron que valores de jerarquía y conservación son más percibidos por los suboficiales reenganchados que por los oficiales. Los suboficiales reenganchados también perciben más todas las actitudes en comparación a los oficiales, demostrando actitudes ambiguas en relación a la mudanza. El valor dominio, característico de organizaciones que 
buscan la supremacía en sus áreas de actuación, presentó valor bajo, explicado por el hecho de que la organización tenga exclusividad de atribuciones garantizada por la Constitución Federal de 1988. La hipótesis de que jerarquía y conservación implican actitud negativa en relación a la mudanza no fue confirmada.

Palabras-clave: Actitudes. Mudanza. Valores. Clima Organizacionale. Policía Militar- Brasília

As rápidas transformações sociais, tecnológicas, econômicas e políticas ocorridas nos últimos anos têm obrigado as organizações a adaptarem-se rapidamente aos novos cenários. Até mesmo instituições públicas bicentenárias, como a Polícia Militar do Distrito Federal (PMDF), veem-se obrigadas a adaptar-se às novas demandas de uma sociedade em constante mutação, principalmente no que tange à valorização dos direitos humanos e ao aprimoramento da qualidade dos serviços prestados, visando a alcançar maior confiança da população (PMDF, 2011).

Com o incremento das taxas de criminalidade nos centros urbanos, a eficiência dos órgãos policiais no controle da criminalidade tem sido colocada em questão, conforme nos aponta Beato (1999). O autor ainda afirma que modificações no âmbito do gerenciamento das atividades policiais, nos processos decisórios e de planejamento podem vir a causar mudanças profundas quanto ao relacionamento da organização policial com o público, bem quanto à eficiência no controle da criminalidade urbana.

Assim, como qualquer organização, a Polícia Militar do Distrito Federal tem o desafio de implementar as mudanças necessárias para adaptar-se a esse ambiente hostil e dar as respostas rápidas que a sociedade exige no controle da criminalidade. No entanto, o processo é difícil, pois, conforme relatam Balogun e Hailey (2004), a taxa de insucesso de todos os programas de mudanças iniciados em diversas organizações é de cerca de 70 por cento.

Nesse cenário, reconhecendo a necessidade de implementar mudanças, especialmente nos seus processos de tomada de decisão, a
Polícia Militar do Distrito Federal adotou uma metodologia, o Método Grumbach, para elaboração e implantação de seu sistema de gestão estratégica, pautado na utilização de cenários prospectivos, conforme PMDF (2011). Tal sistema visa a antecipar, ao máximo, informações relevantes para que o processo de tomada de decisão ocorra alinhado aos objetivos estratégicos da corporação.

No âmbito das Polícias Militares esse projeto de mudança é inédito. Não há qualquer estudo ou pesquisa sobre sua viabilidade e forma de desdobramento adequado em organização semelhante. A falta de base científica e metodologias adequadas deixa as organizações em grande dificuldade para identificar, priorizar e alinhar propriamente os seus recursos e promover mudanças organizacionais sustentáveis (Pascale, Millemann, \& Gioja, 1997).

Uma série de medidas precisa ser implantada no processo de gerenciamento de mudanças planejadas, mas, para tanto, um diagnóstico inicial constitui fator crítico de sucesso. Neiva e Paz (2012) entende ser necessário levantar quais são os valores organizacionais e as atitudes dos indivíduos frente à mudança, com vistas a diagnosticar condições facilitadoras ou não do processo de mudança. Bovey e Hede (2001) sugerem que as crenças pertencentes à cultura organizacional e as atitudes dos indivíduos são responsáveis pelo fracasso dos processos de mudança organizacional.

Em virtude do contexto exposto acima, este artigo estudou a relação entre valores organizacionais e atitudes dos indivíduos frente à mudança na Polícia Militar do Distrito Federal, em um contexto anterior à implantação de seu Plano Estratégico. O estudo descreveu 
ainda as prioridades de valores presentes na organização e as atitudes dos indivíduos em relação às mudanças, além de investigar a influência dos valores organizacionais e de variáveis como sexo e posição hierárquica sobre as atitudes dos indivíduos frente à mudança.

\section{Mudança organizacional}

Ao iniciar uma abordagem sobre mudanças em organizações, torna-se necessário estabelecer as bases e os limites dessa abordagem, haja vista a grande diversidade de abordagens e conceitos relacionados ao assunto.

A mudança organizacional não é uma questão nova na literatura sobre organizações. Entretanto, diante das várias definições e abordagens encontradas sobre mudança, impõe-se um significativo esforço no sentido de delimitação do conceito. Nesse sentido, Lima e Bressan (2003), após verificarem a ausência de consenso na literatura quanto ao conceito de mudança, propuseram a seguinte delimitação conceitual para mudança organizacional:

Qualquer alteração, planejada ou não, nos componentes organizacionais - pessoas, trabalho, estrutura formal, cultura - ou nas relações entre a organização e seu ambiente, que possam ter consequências relevantes, de natureza positiva ou negativa, para a eficiência, eficácia e/ou sustentabilidade organizacional. (Lima \& Bressan, 2003, p. 25)

Os diferentes focos de abordagem da mudança organizacional dão origem a uma variedade considerável de classificações. Neiva e Paz (2012) enumeram alguns aspectos que podem ser considerados na definição de mudança e na proposição de tipologias que abordam a amplitude do fenômeno, entre os quais estão: i) Continuidade versus descontinuidade no tempo; ii) Objeto da mudança (organização como um todo ou apenas subsistemas organizacionais); iii) Intensidade da mudança (intensa ou gradual); iv) Tempo da resposta a eventos externos (antecipação ou reação); v) Velocidade da mudança (de- vagar ou rápida); vi) Intencionalidade versus emergência da mudança; vii) Atores que exercem papel fundamental na mudança (alta direção e/ou membros da organização); viii) Papel do agente de mudança; e ix) Prazo em que ocorre a mudança.

Nadler, Shaw, Walton (1995) apresentam uma tipologia da mudança baseada nos graus de transformação requerida e tempo de resposta a eventos do ambiente. Resultando em quatro dimensões: incremental e radical, proativa e reativa. De forma que mudanças incrementais envolvem pequenas alterações que ocorrem durante períodos de equilíbrio da organização. Mudanças radicais, por sua vez, envolvem mudanças efetivas em períodos de desequilíbrio. A organização capaz de se antecipar às transformações ambientais pode implementar uma mudança proativa. Por outro lado, a resposta da organização pode ter caráter reativo a alterações ou turbulências ambientais. Combinando as quatro dimensões, as mudanças podem ser do tipo ajuste, adaptação, reorientação ou recriação, conforme a Figura 1.

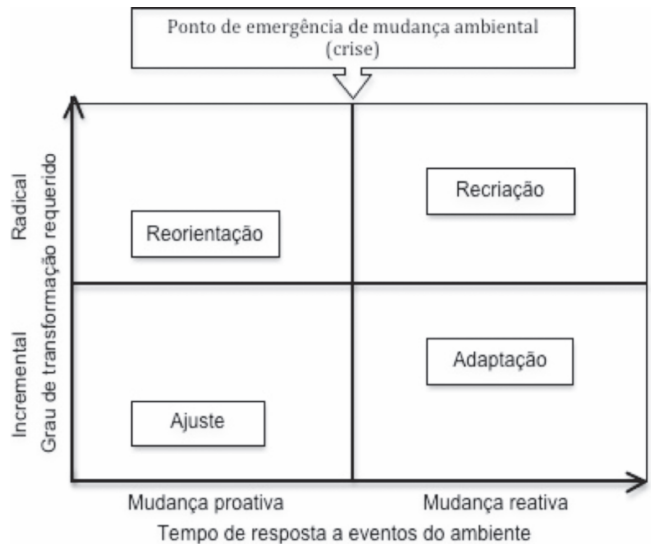

Figura 1. Tipos de mudança organizacional (Nadler et al., 1994).

Weick e Quinn (1999) aprofundaram seus estudos na distinção entre mudança episódica ou radical e mudança contínua ou incremental. Para esses autores, o contraste entre um e outro tipo de mudança está na perspectiva do observador. Enquanto em uma 
perspectiva micro é possível observar as mudanças incrementais do dia a dia (ajuste e adaptação), no nível macro de análise, contempla-se as mudanças ocasionadas por eventos marcantes, crises (reorientação e recriação). Dessa forma, os autores advogam que a mudança é algo natural e está sempre ocorrendo nas organizações. Sob esse aspecto, a intervenção programada seria no sentido de redirecionar as mudanças em andamento.

A compreensão e adoção clara de um ou outro quadro analítico são necessárias para a consecução bem sucedida de um programa de mudanças. Para Nadler et al. (1994), quanto maior antecipação à mudança e quanto menor o grau de transformação requerido, maiores as chances de sucesso de um processo de mudança. Heijden (2002) afirma que a utilização do estudo de cenários prospectivos gera aprendizado organizacional adaptativo, proporcionando respostas mais adequadas, em menor tempo, às novas forças oriundas do ambiente, tornando a organização mais robusta. Os autores convergem quanto à antecipação como fator de sucesso para processos de mudança e sobrevivência organizacional.

A literatura aponta focos de pesquisa decorrentes da variedade de classificações e definições de mudança que disponibilizam lentes, por meio das quais os pesquisadores podem observar o fenômeno tanto do ponto de vista dos indivíduos quanto da coletividade, da organização como um todo quanto de apenas um setor ou departamento e, ainda, das interações dos membros entre si quanto com o ambiente externo em que a organização está inserida. Os indivíduos, segundo Armenarkis e Bedeian (1999), exercem papel central no contexto de mudança, e os critérios comportamentais, atitudinais e afetivos devem ser considerados na análise do sucesso dos programas de mudanças.

Porras e Robertson (1992) defendem que a mudança individual dos membros da organização é pré-requisito para mudança organizacional. Para esses autores:
As intervenções para mudança devem: identificar os comportamentos-chave relacionados aos objetivos da mudança; medir uma linha de base dos comportamentos identificados; analisar funcionalmente para identificar inícios e consequências dos comportamentos; intervir por meio da mudança de inícios e consequências; avaliar para verificar as alterações após a intervenção. (p. 31)

Considerando os critérios comportamentais e afetivos como indicadores importantes no estudo da mudança e citando as atitudes em relação às mudanças como critérios fundamentais para o sucesso das mudanças organizacionais, este estudo avalia tais atitudes e apresenta a literatura de respaldo sobre elas.

\section{Atitudes em relação à mudança}

Considerando a taxa de insucesso dos processos de mudança levantada por Balogun e Hailey (2004), cuja causa apontada é predominantemente a resistência dos indivíduos (Bovey \& Hede, 2001), justificase a análise do processo cognitivo individual como componente da mudança organizacional, uma vez que resistência à mudança é considerada por muitos autores como um construto de ordem individual (Hernandez \& Caldas, 2001). Neiva e Paz (2012) entende que as atitudes dos indivíduos frente à mudança desempenham um papel fundamental na relação entre indivíduos e mudança organizacional. Elas podem ser consideradas como facilitadoras de mudança e são fundamentais para o sucesso dos processos de mudança organizacional.

Segundo Damanpour (1991), as atitudes dos gerentes frente à mudança determinam a participação dos empregados e o sucesso da implantação do programa de mudanças, o que indica que o processo cognitivo dos indivíduos é determinante no que diz respeito à mudança. Neiva, Ros e Paz (2005) verificaram que os indivíduos apresentam atitudes de ceticismo, temor e aceitação frente à mudança. 
Atitudes de aceitação retratam crenças e comportamentos positivos dos membros organizacionais em relação aos processos de mudança. As atitudes de temor retratam o medo da perda de poder, da perda de benefícios e das incertezas dos membros da organização em situações de mudança. As atitudes de ceticismo, por sua vez, retratam crenças e comportamentos negativos em relação aos processos de mudança, principalmente descrédito e não colaboração com programas de mudança.

As atitudes em relação à mudança organizacional são formadas a partir de aprendizagens dos indivíduos em contextos anteriores, durante e posteriores ao processo de mudanças. George e Jones (2001) afirmam que a cultura tem papel preponderante na formação das crenças, atitudes e reações a mudança organizacional. O processo cognitivo individual sofre influência de fatores culturais no nível da organização.

Uma análise interessante, para efeitos de diagnóstico organizacional, é o estudo da relação entre valores organizacionais (como aspectos da cultura organizacional) e a resposta atitudinal dos membros da organização. Essa análise pode revelar as condições facilitadoras ou inibidoras da implantação de mudanças planejadas.

\section{Estudo dos valores}

A temática das investigações sobre valores ocorre sob diversas perspectivas, assim são encontrados estudos na Antropologia, Sociologia e Psicologia, buscando a predição de atitudes e comportamentos (Pattinson, 2004). Porto e Tamayo (2005) mostraram que em trabalhos iniciais de Filosofia, os valores têm sido fonte de reflexão na definição do que é bom ou belo. Os mesmos autores apontam que a contribuição da Psicologia sobre a temática dos estudos sobre valores ocorreram a partir da segunda metade do século XX, quando se buscaram mapear um conjunto de valores que estivessem presentes em todas as pessoas de diferentes culturas.
Além do interesse das diversas áreas, encontra-se na literatura, níveis diferenciados para o estudo dos valores. Ros (2006) os divide em três níveis: o individual, o grupal e o cultural. As teorias de valores mais recentes utilizam os níveis, individual e o cultural (Porto \& Tamayo, 2006). Veiga (2010) apresenta a diferenciação entre esses níveis conceituando os valores individuais como estruturas cognitivas e intrapsíquicas, que podem ser pessoais e sociais. Os valores pessoais tratam sobre os princípios guias da vida das pessoas, já os sociais correspondem à percepção que o indivíduo tem dos princípios referendados pelo grupo. Os valores culturais se constituem como os critérios que auxiliam a solução de problemas da coletividade, eles são as crenças sobre o tipo de comportamento que se estabelece como apropriado em cada situação e acabam funcionando como parâmetros para a justificação das escolhas. Os valores organizacionais também possuem caráter coletivo e se estabelecem como guias para o comportamento humano no contexto organizacional.

\section{Valores organizacionais}

O interesse de pesquisadores sobre o estudo dos valores organizacionais data de várias décadas, a partir de 1980, ocorre um incremento no esforço pelo seu estudo (Agle \& Caldwell, 1999). O mérito das investigações deve ser partilhado pela divulgação dos trabalhos sobre cultura organizacional (Deal \& Kennedy, 1982; Schein, 1996, 1999), que defendem o melhor desempenho organizacional e empresas com culturas fortes (Payne, 2000). Soma-se a isso, a relevância do tema, que se dá tanto na área de pesquisa quanto na área do diagnóstico da gestão organizacional (Tamayo, 2008).

A definição dos valores organizacionais é construída sobre "princípios ou crenças, organizados hierarquicamente, relativos a metas e a comportamentos organizacionais desejáveis que orientam a vida da empresa e estão a serviço de interesses individuais, 
coletivos ou mistos" (Tamayo, 1996, p. 182). É possível notar que servem como guia da vida diária da organização, já que são crenças sobre o que é ou não desejável na organização (Tamayo \& Gondim, 1996); são percebidos facilmente pelos membros da organização, com uma clara função de integração organizacional (Tamayo \& Borges, 2006), pois promovem a adaptação das pessoas ao ambiente (Stainer \& Stainer, 1996) e influenciam comportamentos dos membros, como o comportamento pró-social (Mcneely \& Meglino, 1994).

Para Deal e Kenedy (1982), valores constituem o núcleo da cultura e são os valores compartilhados que definem o caráter fundamental da organização, aquilo que a diferencia das outras. A noção de compartilhado, defendida pelos autores, pressupõe que não há uniformidade e sim convivência com os valores da organização quando esses são diferentes dos valores individuais. Existe um grupo que favorece a difusão dos valores da organização para outros indivíduos, que passam a se comportar de acordo com aqueles valores por meio da socialização, mesmo que opostos aos seus valores pessoais.

Tamayo (2008) argumenta que os valores da organização só existem na mente de seus membros. Deixando claro que cada um dos trabalhadores se constitui em um pontochave para que os valores da organização sejam efetivos. Se não há a subordinação dos valores pessoais aos valores coletivos da empresa, teremos que existe somente uma declaração de intenções. É necessária a aceitação e ratificação dos valores organizacionais por parte dos empregados e que a subordinação dos valores aos organizacionais não signifique sacrifício dos valores pessoais, mas sim reconhecimento da prioridade dos interesses coletivos sobre os individuais.

Considera-se que os valores organizacionais influenciam as respostas atitudinais e comportamentais dos indivíduos (Meglino \& Ravlin, 1998). Segundo Greenwood e Hinings (1996), há várias formas e níveis de envolvimento com valores em qualquer organização, os quais podem ser precipitadores da mudança organizacional. Quanto menor o envolvimento com os valores atuais, mais fácil se torna iniciar um processo de mudança na organização. Entretanto, se o envolvimento com os valores for com tipos de valores mais propícios à mudança, mais fácil fica desenvolver mudanças transacionais que não implicam mudança nos valores da organização.

A literatura nos apresenta três estratégias para identificar os valores de uma organização. A primeira usa os valores pessoais dos membros da organização para a identificação dos valores organizacionais. A segunda avalia os valores por meio da análise de conteúdo sobre os documentos oficiais da empresa, selecionando os valores mais relevantes no discurso oficial da organização. A terceira abordagem consiste em utilizar a percepção dos trabalhadores, como forma de avaliar os valores organizacionais (Tamayo, 2008).

Tamayo (2008) discorre sobre os dois modelos que têm sido usados, a priori, para representar a estrutura dos valores organizacionais, são eles: o modelo cultural e o modelo das motivações pessoais. O primeiro modelo se baseia no fato de que toda organização possui uma cultura, necessitando enfrentar três problemas fundamentais: conciliar os interesses do indivíduo e do grupo; a organização para subsistir deve elaborar uma estrutura, definir papéis, normas, subsistemas organizacionais e suas relações, além de suas estratégias de trabalho; e verificar a relação da organização com o meio ambiente natural e social. Criando três dimensões bipolares que representam um contínuo: i) A relação indivíduo-grupo, pelo eixo autonomia versus conservadorismo; ii) A relação estrutural, pelo eixo hierarquia versus igualitarismo; e iii) A relação do meio ambiente social e natural, pelo eixo harmonia versus domínio, como alternativas para os problemas apresentados. A partir desse modelo foi construído e validado o Inventário de Valores Organizacionais - IVO (Tamayo, Mendes \& Paz, 2000). 
O segundo modelo demanda a existência do isomorfismo motivacional, no que se refere aos valores pessoais e organizacionais. Assim, segundo Tamayo (2008), o isomorfismo motivacional se constitui em uma correspondência biunívoca dos tipos motivacionais de valores pessoais do trabalhador e dos valores organizacionais. Segundo Schwartz (2005), as motivações básicas dos indivíduos são construídas sobre dez tipos motivacionais, autodeterminação, estimulação, hedonismo, realização, poder, segurança, conformidade, tradição, benevolência e universalismo, que apresentam metas específicas. O presente modelo postula que na organização existem metas axiológicas que correspondem a cada uma das motivações básicas, mesmo que ocorra a fusão de dois ou mais tipos motivacionais adjacentes para que se constitua a relação biunívoca. Por exemplo, universalismo e benevolência, representados por um único fator, que expressa a preocupação com a coletividade (Tamayo, 2008). Partiu deste modelo a construção e validação do Inventário de Perfis de Valores Organizacionais - IPVO (Oliveira \& Tamayo, 2004).

\section{Objetivos e desenho do estudo}

O presente trabalho constitui-se de estudo na Polícia Militar do Distrito Federal, cujo objetivo é descrever e testar a relação entre os valores organizacionais e as atitudes dos indivíduos frente à mudança por meio de instrumentos validados psicometricamente.

Esta pesquisa caracteriza-se como de natureza correlacional, pois, pretendeu-se analisar o impacto da variável valores organizacionais na variável atitude frente à mudança e é, ainda descritiva, uma vez que visa descrever a percepção dos participantes quanto às variáveis de pesquisa. Quanto à estratégia, pode ser definida como quantitativa uma vez que se valeu de um questionário fechado com respostas pré-definidas. Utilizou-se então o método de levantamento, pois o objetivo é generalizar a descrição quantitativa da amostra colhida para a população estudada.
Neste estudo foi realizado o levantamento dos valores organizacionais e a análise da relação entre os valores encontrados e as atitudes frente à mudança, por parte dos membros da organização,

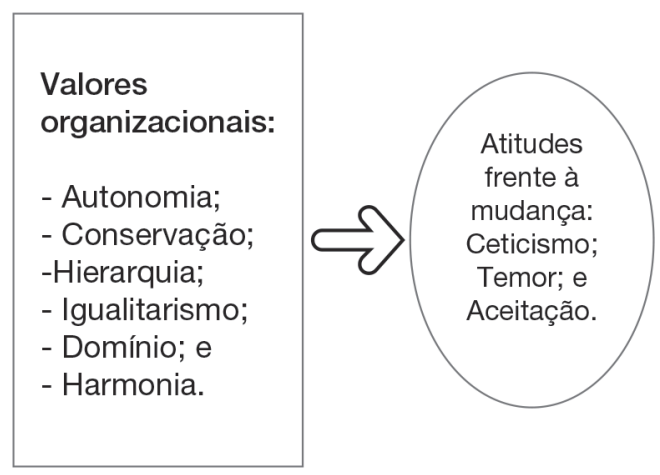

Figura 2. Representação do modelo de pesquisa

Conforme Figura 2. Os valores foram levantados com a aplicação do Inventário de Valores Organizacionais, de Tamayo et al. (2000). As atitudes foram levantadas com a utilização do instrumento validado por Neiva, Ros e Paz (2005), de forma que as atitudes positivas estão relacionadas à aceitação, enquanto atitudes negativas à mudança estão ligadas a ceticismo e temor. Por conseguinte, foi testada a hipótese de que valores de hierarquia e conservação resultam em atitudes negativas em relação à mudança.

\section{Definição das variáveis}

As atitudes frente à mudança foram consideradas como aceitação, temor e ceticismo, de forma que atitudes de aceitação retratam crenças e comportamentos positivos dos membros organizacionais em relação aos processos de mudança. As atitudes de temor retratam o medo da perda de poder, da perda de benefícios e das incertezas dos membros da organização em situações de mudança. As atitudes de ceticismo, por sua vez, retratam crenças e comportamentos negativos em relação aos processos de mudança, principalmente descrédito e não colaboração com programas de mudança. 
Os valores são abordados em três dimensões: a relação indivíduo-grupo, pelo eixo de autonomia versus conservação; a relação estrutural, pelo do eixo hierarquia versus estrutura igualitária; e a relação do meio ambiente social e natural, pelo do eixo harmonia versus domínio.

Valores de conservação retratam a manutenção do status quo, enquanto valores de autonomia estão relacionados à criatividade e responsabilidade individual e testagem de inovações. Valores de hierarquia retratam diferenciação e status, dando ênfase à autoridade, fiscalização e supervisão, enquanto valores de estrutura igualitária expressam justiça social, igualdade e responsabilidade. Valores de domínio, que caracterizam a relação organização-ambiente, retratam a exploração do meio ambiente e o domínio sobre o mercado com imposição de produtos e imagem, enquanto valores de harmonia retratam respeito à natureza e bom contato com outras organizações.

\section{Método}

Foi escolhido o método de levantamento para este estudo, por ser apropriado em caso de tempo exíguo para a coleta de dados (Creswell, 2010) e por proporcionar boa generalização a partir de pequenas amostras.

\section{Caracterização da Organização}

A Polícia Militar do Distrito Federal é um órgão do poder executivo para preservação da ordem pública e exercício de atividades de polícia ostensiva, conforme previsto pela Constituição Federal de 1988, em seu artigo 144. Conta com um efetivo de aproximadamente 15.000 mil policiais na ativa, sendo 1.180 oficiais e 13.100 praças. Os policiais militares são juridicamente classificados como servidores especiais-militares do Distrito Federal e regidos por estatuto próprio.

A PMDF iniciou um processo de mudança com ampla reestruturação organizacional e lei de promoções que alterou a forma de ascensão funcional dos seus servidores. Como parte deste processo, a publicação do Plano Estratégico 2011-2022, possibilitou a orientação dos processos corporativos para uma gestão mais ágil e com orientação para resultados.

A etapa seguinte desse processo iniciou-se após a publicação do Plano Estratégico 20112022, em fevereiro de 2011. Há a previsão de aproximadamente 300 iniciativas estratégicas para que os objetivos estabelecidos sejam atingidos.

\section{Participantes}

A amostragem foi não probabilística, por conveniência e de fase única, englobando todos os postos e graduações que constituem a hierarquia organizacional. Não foi estabelecido tamanho mínimo da amostra, de maneira que foram coletados dados de 567 participantes, entretanto, foram considerados válidos 467, viabilizando qualquer tipo de análise estatística.

A amostra apresentou idade média de 38 anos, dos quais 93,5\% são do sexo masculino. Quanto à escolaridade, 51,2\% possuem nível superior completo e 20,2\% nível de especialização. Quanto ao nível hierárquico ocupado pelos participantes, $21,7 \%$ são oficiais e $78,3 \%$ são praças, sendo que em um extremo $1,2 \%$ são coronéis e no outro extremo $25,7 \%$ são soldados.

\section{Instrumento}

Duas escalas foram empregadas, a primeira, o inventário de valores organizacionais (IVO) validado por Tamayo, Mendes e Paz (2001), cuja confiabilidade, número de itens e os valores representados são verificados na Tabela 1 e uma escala para levantamento de atitudes dos indivíduos frente à mudança organizacional. 


\section{Tabela 1.}

Valores, Número de Itens e Confiabilidade

\begin{tabular}{lll}
\hline Polos & Número de itens & Alfas de Cronbach \\
\hline Autonomia & 4 & 0,74 \\
Igualitarismo & 3 & 0,76 \\
Hierarquia & 4 & 0,72 \\
Conservação & 3 & 0,72 \\
Domínio & 4 & 0,83 \\
Harmonia & 6 & 0,86
\end{tabular}

A segunda é a escala de atitudes frente à mudança organizacional, validada por Neiva, Ros e Paz (2005). Essa escala possui três fatores (ceticismo, temores e aceitação) que representam as três atitudes típicas apresentadas pelos indivíduos em situação de mudança organizacional. A escala foi submetida à análise paralela, análise fatorial exploratória e confirmatória, sendo esta última realizada com utilização da técnica de modelagem por equações estruturais. A Tabela 2 descreve resumidamente a confiabilidade e o número de itens de cada dimensão do instrumento.

\section{Tabela 2}

Atitudes, Número de Itens e Confiabilidade

\begin{tabular}{lll}
\hline Polos & Número de itens & Alfas de Cronbach \\
\hline Ceticismo & 18 & 0,95 \\
Temores & 9 & 0,88 \\
Aceitação & 9 & 0,83 \\
\hline
\end{tabular}

\section{Procedimento}

Após autorização da PMDF, a coleta de dados deu-se por conveniência, pelo envio de questionários disponíveis na internet e administrados on-line. O link para os questionários foi enviado a vários endereços eletrônicos corporativos e disponibilizado na intranet da organização em estudo, por um período de 30 trinta dias. Esse procedimento foi escolhido devido à automatização do processo de alimentação dos dados no software estatístico de análise e também ao baixo custo da utilização de tal ferramenta. Como ponto fraco desse processo, há a dificuldade de comunicação e consequente sensibilização do participante quanto ao seu preenchimento. Nesse ensejo, era garantido aos participantes o anonimato e o sigilo das respostas conforme explicitado no Termo de Consentimento Livre e Esclarecido. Em média, quinze minutos foram suficientes para completar a participação na pesquisa.

\section{Análise dos Dados}

As análises descritivas e inferenciais foram realizadas por meio do SPSS 17. As variáveis em estudo não apresentaram distribuição normal. Diante disso, foram realizadas análises de 
estatística não paramétrica para verificação das diferenças das médias obtidas em cada variável e subsequente ordenação e executadas regressões logísticas para verificar as relações entre valores e atitudes.

\section{Resultados e Discussões}

A seguir, são apresentados os resultados das análises das variáveis valores organizacionais e atitudes frente à mudança.

\section{Valores Organizacionais - Prioridades Axiológicas}

Os testes não paramétricos realizados foram o de Kruskal-Wallis e o de Mann-Whitney, para verificação da diferença de médias e confirmar se os polos axiológicos que apresentam maior média realmente são aqueles que mais caracterizam a organização. Os resultados sobre a percepção dos valores organizacionais praticados indicaram que os polos conservação e hierarquia são os mais característicos da organização, conforme descrito na Tabela 3.

\section{Tabela 3.}

Prioridades axiológicas presentes na organização

\begin{tabular}{llll}
\hline Níveis & Valores & Média & DP \\
\hline 1 & Conservação & $\mathbf{3 , 3 8}$ & $\mathbf{1 , 2 7}$ \\
& Hierarquia & $\mathbf{3 , 2 9}$ & $\mathbf{1 , 2 1}$ \\
2 & Igualitarismo & 2,72 & 1,39 \\
& Harmonia & 2,71 & 1,34 \\
4 & Autonomia & 2,53 & 1,36 \\
\hline
\end{tabular}

$N=469$ e $p \leq 0,05$

Foram encontrados quatro níveis hierárquicos estatisticamente diferentes entre si. No primeiro nível, encontram-se os polos conservação e hierarquia, que são os mais praticados na instituição. No segundo nível, estão igualitarismo e harmonia. No terceiro, autonomia e no quarto, domínio.

A hierarquia é capaz de realizar um mapeamento total da instituição, bem como verificar como as relações sociais são percebidas e realizadas pelo grupo, constituindo-se de um importante aspecto para o entendimento da identidade do militar. A organização como um todo está pautada em valores que enfatizam a observância das normas e tradições, das quais a hierarquia é a forma encontrada para garantir o cumprimento da missão organizacional, por meio da divisão clara de funções, do controle e da fiscalização. Conforme nos esclarece Nascimento (2010), os policiais que ocupam posições de maior nível funcional na hierarquia Policial Militar percebem um ambiente mais favorável, o que se justifica, em primeiro lugar, pela internalização das normas e dos valores da organização. 
Tais valores são sociocêntricos, conforme Tamayo et al. (2000), de forma que os interesses dos indivíduos não são vistos como diferentes dos da organização. No entanto, observa-se que, no segundo nível, há a percepção de valores relacionados ao igualitarismo, que expressam o desejo de diminuição dos níveis de autoridade e preocupação com o bem-estar do outro. Isso pode indicar a diferença entre a estrutura organizacional rígida, hierarquizada e a organização informal, mais igualitária.

Sobre tal aspecto, Monjardet (2002) nos esclarece que a organização policial é uma entidade particular, no sentido em que sua estrutura hierárquica representa o modelo mais rígido de autoridade, que se baseia em ordens, comandos e disciplina, entretanto, o autor ressalta que, para manter o funcionamento eficaz, deve haver uma organização informal, com a finalidade de se implementar mecanismos de cooperação no reconhecimento mútuo de uma interdependência funcional muito estreita.

Já o polo domínio, no quarto nível, demonstra que a organização não tem ênfase na imposição de sua imagem organizacional, no domínio de recursos materiais, tecnologia e conhecimento, e na obtenção do predomínio em sua área de atuação (Tamayo et al., 2000). Tal resultado pode ser explicado devido à condição de organização pública, com missão organizacional definida com exclusividade pela Constituição Federal de 1988.

De forma próxima a esse assunto e referindo-se especificamente ao trabalho do policial, Brito e Souza (2004) comentam que ocorrem intervenções que buscam otimizar e democratizar o trabalho policial, entretanto, injunções múltiplas são obstáculos para a correta execução do mandato policial, afastando a organização policial da obtenção do domínio em seu espaço de ação, haja vista as escassas condições de infraestrutura, das deficiências na profissionalização.

Ainda conforme relatam os autores Brito e Souza (2004), a representação de profissionalização faz referências às percepções que os policiais têm de sua profissionalização, de seu papel social. Assim, questionam como as relações de seu trabalho com as esferas institucional e política podem auxiliar ou interromper a execução de suas tarefas e funções.

Atitudes frente à mudança

Os respondentes destacaram a atitude de temor, enquanto as atitudes ceticismo e aceitação encontraram-se no mesmo patamar, ver Tabela 4.

\section{Tabela 4.}

Atitudes frente à mudança presentes na organização

\begin{tabular}{llll}
\hline Níveis & Valores & Média & DP \\
\hline 1 & Temor & 2,75 & 0,78 \\
2 & Ceticismo & 2,62 & 0,81 \\
& Aceitação & 2,62 & 0,74 \\
\hline
\end{tabular}

$\mathrm{N}=469$ e $\mathrm{p} \leq 0,05$

Fonte: Dados da pesquisa 
Atitudes de temor frente às mudanças são as mais percebidas pelos membros da organização. Demonstram a percepção de que há medo da perda de poder e de benefícios enquanto que aceitação e ceticismo no mesmo nível podem indicar ambiguidade de atitudes em relação à mudança organizacional, segundo Neiva e Paz (2012). Aqui, há uma predominância de temor, seguido de ambiguidade nas atitudes por parte de grupos internos da organização. Parece que os policiais investigados temem as mudanças propostas em virtude das possíveis perdas financeiras e de status, além das profundas alterações nos valores e estrutura organizacional e contexto de trabalho propostos. Muitos referenciais dos policiais podem ser afetados pelo processo de mudanças.

Diferenças entre grupos de oficiais e praças ao se comparar valores e atitudes

A primeira análise apresenta as diferenças entre as médias de dois grupos de policiais, os oficiais (nível de gestão organizacional) e praças (nível de execução organizacional) para os valores e atitudes.

\section{Tabela 5.}

Valores segundo níveis hierárquicos

\begin{tabular}{lllll}
\hline Valores & $\begin{array}{l}\text { Praças } \\
\text { Média }\end{array}$ & DP & $\begin{array}{l}\text { Oficiais } \\
\text { Média }\end{array}$ & DP \\
\hline Conservação & 3,50 & 1,30 & 3,00 & 1,08 \\
Hierarquia & 3,41 & 1,24 & 2,94 & 1,05 \\
Igualitarismo & 2,64 & 1,49 & 2,97 & 0,99 \\
Harmonia & 2,76 & 1,40 & 2,53 & 1,10 \\
Autonomia & 2,47 & 1,46 & 2,70 & 0,99 \\
Domínio & 2,45 & 1,49 & 2,25 & 1,21 \\
\hline
\end{tabular}

$N=469$ e $p \leq 0,05$

Os resultados apontaram diferenças, enquanto o círculo de praças apresentou maiores médias para os polos conservação, hierarquia, harmonia e domínio, o círculo dos oficiais percebem mais valores de igualitarismo e autonomia. Tais resultados encontram respaldo no trabalho desenvolvido por Nascimento (2010), ao estabelecer que, em virtude do posicionamento hierárquico da instituição Policia Militar, a maior valoração do policial tanto interna quanto externa se dirige aos papéis desempenhados pelos oficiais e por aqueles policiais praças graduados, subtenentes e sargentos. Tal situação leva a um desvirtuamento na maneira em que o subordinado se percebe, já que ao seu trabalho é atribuído um valor menor do que o dos seus superiores hierárquicos.

Justificam-se assim, os valores conservação e hierarquia como os mais percebidos pelas praças, o que pode ser explicado pela posição na estrutura hierárquica da organização, bem como o fato de perceberem mais temor, já que nesse círculo hierárquico há menores possibilidades de contornar o desconforto causado por mudanças. 
Pesquisas realizadas por Nascimento, Torres e Pimentel (2011) estabelecem que o conhecimento das atitudes frente à polícia pode ser muito útil para a sociedade e para a própria instituição policial, já que possibilita verificar como determinados grupos a avaliam. Nesse sentido, o conhecimento de tais avaliações pode ser um feedback importante do comportamento da polícia, o que pode ajudar a reforçar procedimentos ou mesmo redefini-los, tendo em vista uma melhor atuação para e com a sociedade. Nesse sentido, ao analisar a relação entre atitudes e os níveis hierárquicos, praças e oficiais, constata-se diferença na percepção de atitudes em relação à mudança entre os círculos hierárquicos de oficiais e praças, de forma que praças apresentam médias mais altas para todas as atitudes. Nota-se, assim, que tais achados evidenciam que mudanças organizacionais na polícia são relativamente difíceis de implementação, principalmente no circulo das praças, que são os atores policiais que estão no atendimento direto da população. Os testes demonstraram que não existe diferença na percepção de atitudes entre os sexos dos policiais.

\section{Tabela 6.}

Atitudes segundo níveis hierárquicos

\begin{tabular}{lllll}
\hline Atitudes frente à & $\begin{array}{l}\text { Praças } \\
\text { Média }\end{array}$ & DP & $\begin{array}{l}\text { Oficiais } \\
\text { Média }\end{array}$ & DP \\
\hline Temor & 2,82 & 0,79 & 2,56 & 0,73 \\
Ceticismo & 2,70 & 0,81 & 2,40 & 0,74 \\
Aceitação & 2,67 & 0,77 & 2,48 & 0,61 \\
\hline
\end{tabular}

$\mathrm{N}=469$ e $\mathrm{p} \leq 0,05$

Relação entre valores organizacionais e atitudes frente à mudança

Foram realizadas regressões logísticas para avaliar as relações entre os valores organizacionais e atitudes frente à mudança. As variáveis de atitude foram dicotomizadas para assumir valores fraco ou forte. Os resultados mostraram que o modelo para predição da atitude ceticismo tem um percentual total de 78,3\% de acerto, entretanto não prediz valores fracos.

Tabela 7.

Regressão Valores x Atitudes

\begin{tabular}{lllllll}
\hline Atitude & B & $\begin{array}{l}-2 \text { Log } \\
\text { likelihood }\end{array}$ & Wald & $\begin{array}{l}\text { Cox \& } \\
\text { Snell R2 }\end{array}$ & $\begin{array}{l}\text { Nagelkerke } \\
\text { R2 }\end{array}$ & $\begin{array}{l}\text { Hosmer e } \\
\text { Lemeshow }\end{array}$ \\
\hline Ceticismo & 1,280 & 471,678 & 130,851 & 0,041 & 0,063 & Sig. 0,236 \\
Temor & 1,582 & 416,096 & 165,972 & 0,026 & 0,043 & Sig. 0,589 \\
Aceitação & 1,370 & 462,867 & 142,267 & 0,021 & 0,033 & Sig. 0,805 \\
\hline
\end{tabular}

As estatísticas Cox \& Snell e Nagelkerke apresentaram valores baixos para todas as variáveis, de forma que o maior poder preditivo indicado para o modelo foi para a atitude ceticismo, com valor de 6,3\% (Nagelkerke) e o menor foi para a atitude aceitação, com valor de 2,1\% 
(Cox\&Snell). O teste de Hosmer e Lemeshow foi não significativo para todas as atitudes, o que implica em dizer que não há diferença estatisticamente significativa entre os valores observados e os estimados pelo modelo.

O modelo obtido apresentou coeficiente significativo apenas para a variável domínio em relação à atitude ceticismo, cujo valor de $\mathrm{B}$ foi de - 0,307 com significância de 0,033. Quanto mais a organização é percebida como influente sobre outras organizações, menos se evidencia um ceticismo em relação às mudanças. Tais resultados corroboram a influência do contexto sobre as atitudes positivas em relação à mudança, na medida em que as relações com outras organizações e um contexto competitivo afetam a ocorrência mais frequente de mudanças, o que torna o indivíduo a se adaptar melhor as alterações. Tal resultado não corrobora estudos anteriores (Neiva \& Paz, 2012).

As regressões não confirmaram a hipótese de que valores de hierarquia e conservação implicam em atitudes negativas em relação à mudança, hipótese esta que também foi testada por Neiva e Paz (2012) e considerada inconclusiva. Veiga (2010) também não encontrou relações entre valores organizacionais, normas e comportamento proativo. Outros estudos apresentam questionamentos sobre a relação entre valores e atitudes (Feather, 1985, 1989; Homer \& Kahle, 1988). Contudo, Moreno (2006) encontrou relações significativas, mas com efeito reduzido, de valores individuais sobre atitudes no contexto de uso de álcool. Muitos autores lançam questionamentos no sentido de que valores tratam de princípios que transcendem situações e as atitudes focam objetos específicos. As atitudes são menos centrais e mais dirigidas a objetos que os valores, os valores transcendem objetos e situações. As atitudes predispõem os indivíduos a agir de determinada forma em relação a um objeto (Grube, Mayton \& Ball-Rokeach, 1994). Tal diferença pode explicar por que os valores não se apresentaram como preditores das atitudes em relação às mudanças. Contudo, os valores estudados aqui dizem respeito aos valores organizacionais que tratam de princípios que transcendem situações e se reportam a uma coletividade (a organização), o que os diferencia dos valores humanos que realmente focam aspectos individuais que transcendem situações.

Este trabalho, como qualquer outro, possui méritos e limitações. Do ponto de vista teórico, o estudo lança questionamentos sobre a relação entre valores e atitudes, na medida em que não corrobora tal relação. Essa relação precisa ser melhor abordada no caso de valores organizacionais. Talvez a questão esteja centrada na medida de valores organizacionais que pode não refletir adequadamente o construto.

O maior mérito está em iniciar uma análise em uma organização militar de segurança pública, carente de um olhar mais profundo dos estudiosos. Em um caráter prático, o levantamento dos valores organizacionais e das atitudes dos membros da organização poderá subsidiar o processo de implantação das iniciativas do Plano Estratégico lançado em fevereiro de 2011. Para uma organização militar, a não confirmação da hipótese de que valores de hierarquia e conservação implicam em atitudes negativas em relação à mudança é positiva. Se a percepção de valores de hierarquia e conservação por si só não afeta as atitudes tornando-as negativas em relação à mudança, há possibilidade de a organização desenvolver atitudes positivas dos policiais em relação às mudanças. Tais resultados sugerem uma investigação mais acurada da relação entre a cultura organizacional e uma provável resistência por parte dos indivíduos. A cultura organizacional tem sido responsabilizada pelas resistências às mudanças organizacionais (George \& Jones, 2001) e tais resultados lançam dúvidas sobre isso, na medida em que o fato de valores organizacionais de hierarquia e conservação não explicarem, isoladamente, as atitudes negativas em relação às mudanças.

Uma questão do estudo está no uso de amostra específica que possui limitações 
para generalização. Além disso, o estudo trata de construtos avaliados em uma situação específica que remete a mudanças no contexto de uma organização policial, caracterizada por sua estrutura estável, hierarquizada e conservadora (Brito \& Souza, 2004).
Como outra limitação, este estudo tem a ausência de uma abordagem qualitativa, complementar aos instrumentos utilizados. É sugerida uma pesquisa qualitativa para aprofundar a compreensão dos resultados aqui apresentados.

\section{Leandro Guimarães Rodrigues}

Mestrando em Administração pela Universidade de Brasília. Capitão da Polícia Militar do Distrito Federal. E-mail: leandroguimaraes2@gmail.com

\section{Thiago Gomes Nascimento}

Doutorando em Administração pela Universidade de Brasília. Capitão da Polícia Militar do Distrito Federal. E-mail: tgn.1980@gmail.com

\section{Elaine Rabelo Neiva}

Doutora em Psicologia Social do Trabalho e das Organizações pela Universidade de Brasília. Professora do Programa de Pós-graduação em Psicologia Social do Trabalho e das Organizações da UnB. E-mail: elaine_neiva@uol.com.br

\section{Endereço para envio de correspondência}

QNL 17, conj. F casa 18. Taguatinga Norte, Brasília, DF. CEP: 72.151-706

Recebido 10/03/2013, Aprovado 16/10/2013. 
Agle, B. R., \& Caldwell, C. B. (1999). Understanding research on values in business: A level of analyses framework. Business Society, 38(3), 326-387.

Armenakis, A. A., \& Bedeian, A. G. (1999). Organizational change: a review of theory and research in the 1990s. Journal of Management, 25(3), 293-315. doi: 10.1177/014920639902500303

Balogun, J., \& Hailey V. H. (2004). Exploring Strategic Change. (2th ed.). Londres: Prentice Hall.

Bovey, W. H. \& Hede, A. (2001). Resistance to organizational change: the role of cognitive and affective processes. Leadership \& Organization Development Journal, 22(8), 372-382. doi: 10.1108/01437730110410099

Brito, A. S., \& Souza, L. (2004). Representações sociais de policiais civis sobre profissionalização. Sociologias, Porto Alegre, 6(12), 304-327. doi: http://dx.doi.org/10.1590/S1517 45222004000200011

Beato, C. C. (1999). Ação e estratégia das oganizações policiais. Belo Horizonte: Departamento de Sociologia e Antropologia, UFMG.

Creswell, J. W. (2010). Projeto de pesquisa: métodos qualitativo, quantitativo e misto. Porto Alegre: Artmed.

Damanpour, F. (1991). Organizational innovation: a meta-analysis of effects of determinants and moderators. Academy of Management Journal, 34(3), 555- 590. doi: 10.2307/256406.

Deal, T. E., \& Kennedy, A. A. (1982). Corporate Cultures: The Rites and Rituals of Corporate Life, Harmondsworth, Penguin Books, 1982.

Feather, N. T. (1985). Attitudes, values and attributions: Explanations of unemployment. Journal of Personality and Social Psychology, 48(4), 876-889. doi: 10.1037/0022-3514.48.4.876

Feather, N. T. (1989). Attitudes towards high achiever: The fall of the tal poppy. Australian Journal of Psychology, 41, 239-267.

George, J. M., \& Jones, G.R. (2001). Towards a process model of individual change in organization. Human Relations, 54(4), 419-444. doi: 10.1177/0018726701544002.
Greenwood, R., \& Hinings, C. R. (1996). Understanding radical organizational change: Bringing together the old and the new institutionalism. Academy of Management Review, 21(4), 10221054. doi. 10.5465/AMR.1996.9704071862.

Grube, J. W., Mayton, D., \& Ball-Rokeach, S. J. (1994). Inducing change in values, attitudes and behaviors: belief system theory and the method of value self-confrontation. The Journal of Social Issues, 50(4), 153-173. doi: 10.1111/j.1540-4560.1994.tb01202.x.

Heijden, K. Van Der. (2002). The six sense: accelerating organizational learning with scenarios. New York: John Wiley \& Sons.

Hernandez, J. M. D. C., \& Caldas, M. P. (2001). Resistência à mudança: uma revisão crítica. Revista de Administração de Empresas, 41(2), 31-45. doi http://dx.doi.org/10.1590/S003475902001000200004.

Homer, P. M., \& Kahle, L. (1988). A structural equation test of the value-attitude-behavior hierarchy. Journal of Personality and Social Psychology, 54, 638-646. doi: 10.1037/00223514.54.4.638

Lima, S. M. V., \& Bressan, C. L. (2003). Mudança organizacional: uma introdução. In S. M. V. Lima, (Org.), Mudança organizacional: teoria e gestão. Rio de Janeiro: FGV.

Meglino, B. M., \& Ravlin, E. C. (1988). Individual values in organizations: concepts, controversies, and research. Journal of Management, 24(3), 351-389. doi: 10.1177/014920639802400304

Moreno, J. (2006). Valores, actitudes hacia el alcohol Y consumo en adolescentes varones. Límite: Revista de Filosofia e Psicología, 1(13), 195-211.

Monjardet, D. (2000). O que faz a polícia (M. A. L. Barros, trad.). São Paulo: Edusp.

Mcneely, B. L., \& Meglino, B. M. (1994). The role of dispositional and situational antecedents in prosocial organizational behavior: An examination of the intended beneficiaries of prosocial behavior". Journal of Applied Psychology, 79(6), 836-844.

Nadler, D. A., Shaw, R. B., Walton, A. E., et al. (1995). Discontinuous Change: leading organizational transformation. San Francisco: The Jossey-Bass Management series. 
Nascimento, T. G. (2010). Polícia - Uma Identidade em Discussão: Construção, Validação e Aplicação de um Instrumento. Dissertação de Mestrado. Universidade de Brasília, Brasília, DF.

Nascimento, T. G., Torres, C. V., \& Pimentel, C. E. (2011). Evidências de validade e Precisão da Escala de Atitudes Frente à Polícia. Revista Brasileira de Segurança Pública, 9, 42-56.

Neiva, E. R., \& Paz, M. G. T. (2012). Percepção de mudança individual e organizacional: o papel das atitudes, dos valores, do poder e da capacidade organizacional. Revista de Administração - RAUSP, 47(1), 22-37. doi: 10.5700/rausp1023

Neiva, E. R., Ros, M. \&, Paz, M. G. T. (2005). Atitudes towards organizational change: validation of a scale. Psychology in Spain, 9(1), 81-90.

Oliveira, A. F., \& Tamayo, A. (2004). Perfis de valores organizacionais. Revista de Administração - RAUSP. 39(2), 129-140.

Pascale, R., Millemann, M., \& Gioja, L. (1997). Changing the Way We Change. Harvard Business Review, 75(6), 126-139.

Poícia Militar do Distrito Federal - PMDF. (2011). Plano Estratégico 2011-2022: Planejando a Segurança Cidadã do Distrito Federal no Século XXI. Brasília, DF: Zit Gráfica e Editora.

Porras, J. I., \& Robertson, P. J. (1992). Organizational development: theory, practice, research. In M. D. Dunnette, \& L. M. Hough (Eds.). Handbook of organizational psychology (2nd ed., Vol. 3), 719-822. Palo Alto, C.A: Consultant Psychology Press.

Porto, J. B., \& Tamayo, A. (2005). Valores organizacionais e civismo nas organizações. RAC Revista de Administração Contemporânea, 9(1), 35-52.

Porto, J. B., \& Tamayo, A. (2006). Influência dos valores laborais dos pais sobre os valores laborais dos filhos. Psicologia Reflexão e Crítica, 19(1), 151-158. doi: http://dx.doi.org/10.1590/S1415-65552005000100003

Ros, M. (2006). Psicologia social dos valores: uma perspective histórica. In M. Ros, \& V. V. Gouveia (Orgs.). Psicologia Social dos Valores Humanos: desenvolvimentos teóricos, metodológicos e aplicados (pp. 23-53). São Paulo: SENAC.
Schein, E. H. (1996). The corporate culture survival guide: sense and nonsense about culture change. São Francisco, CA: Josey-Bass.

Schein, E. H. (1999). Culture: the missing concept in organizational studies. Administrative Science Quarterly, 44, 229-241.

Stainer, A., \& Stainer, L. (1996). Productivity and performance: a value-based approach. Journal of Applied Management Studies, 5(1), 1-13.

Schwartz, S. (2005). Valores humanos básicos: seu contexto e estrutura intercultural. In A. Tamayo, \& J. B. Porto (Orgs.). Valores e comportamento nas organizações (pp. 21-55). Petrópolis: Vozes.

Tamayo, A. (1996). Valores organizacionais. In A. Tamayo, J. E., Borges-Andrade, \& W. Codo (Orgs.), Trabalho, Organizações e Cultura (pp. 175-193). São Paulo: Cooperativa de Autores Associados.

Tamayo, A. (2008). Valores Organizacionais. In: Siqueira, M. M. M. (Org.), Medida do Comportamento Organizacional: Ferramentas de diagnóstico e de gestão, (pp. 309-340). Porto Alegre: Artmed,

Tamayo, A., \& Borges, L. de O. (2006). Valores do trabalho e das organizações. In M. Ros, \& V. V. Gouveia (Orgs.), Psicologia Social dos Valores Humanos (pp. 397-431). São Paulo: Senac.

Tamayo, A., \& Gondim, M. G. C. (2000). Escala de valores organizacionais. Revista de Administração, 31(2), 62-72.

Tamayo, A., Mendes, A. M., \& Paz, M. G. T. (2000). Inventário de Valores Organizacionais. Estudos de Psicologia.(Natal) 5(2), 289-315. doi: http://dx.doi.org/10.1590/S1413-294X2000000200002.

Veiga, H. M. S. (2010). Comportamento Próativo: relações com valores organizacionais, estímulos e barreiras à criatividade nas organizações e normas sociais. Tese de doutorado. Pós-graduação em Psicologia Social, do Trabalho e das Organizações. Universidade de Brasília, Brasília, DF.

Weick, K.E., \& Quinn, R. E. (1999). Organizational Change and Development. Annual Review of Psychology, 50, 361-386. doi. 10.1146/annurev.psych.50.1.361. 